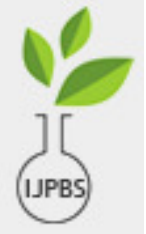

\section{International Journal of Pharma and Bio Sciences}

Review Article

Neurobiology

\title{
Act of Phytochemical-Based Antioxidants in Neurodegenerative Disorders Utilizing Indian Medicinal Plants
}

\author{
Navya Raj MP'* Pooja G Singh' and Sushma BV². \\ 'Research scholar, Department of Nutrition \& Dietetics, Faculty of Life Sciences, JSSAHER, Mysuru. India \\ ${ }^{2}$ Assistant professor, Department of Nutrition \& Dietetics, Faculty of Life Sciences, JSSAHER, Mysuru.India
}

\begin{abstract}
Neurodegenerative diseases are multifactorial nervous system deteriorating conditions that concern over 30 million aging populations worldwide. The effect of protein malfunction or defective trafficking is neurodegenerative disease, such as Alzheimer disease [AD], Parkinson's disease [PD], Huntington's and Amyotrophic lateral sclerosis disorders. Furthermore, mitochondrial dysfunction, oxidative stress / age-linked environmental factors have also been involved. Prolonged use of synthetic medications could lead to adverse side effects for these illnesses. Henceforth herbal therapy attracts much attention rather than a pharmaceutical therapy is favoured. Indeed, several research studies have identified use of medicinal plants and their components for drug production, and recently more than 100 new medicines are now being established clinically. Accumulative data shows that nutraceuticals property is critical for cognition optimisation and risk mitigation. The study explores the role of phytochemical based antioxidants in cognitive and adverse signal transduction events, with a special focus on the Mediterranean diet [MeDi] comprising bioactive compounds like - xanthophyll carotenoids and omega-3 fatty acids. These phytochemical compounds are capable of improving cognition, considering their selective brain involvement and their specifically oxidative damage and inflammation. The objective of this study is to detail the molecular mechanisms of some Ayurvedic plants signal transduction and locations of operation. It is hoped that this review further helps to examine a new therapeutic recommendations and further research in clinical trials on the use of poly-herbal Ayurvedic medicine for the treatment and prevention of dementia. It is expected to increase the ease in the usage of Ayurveda-based knowledge base combined with combined scientific and high-performance screening strategies in the drug research and development campaign, while offering new practical guidelines for neurosurgical diseases linked to age.
\end{abstract}

Keywords: Neurodegenerative, protein malfunction, oxidative stress, MeDi, Bioactive compounds, omega-3-FA, cognition, AD, PD, Medicinal plants.

$\begin{array}{lllll}\text { Article History } & \text { Date of Receiving } & 01 \text { March } 2021 & \text { Date of Revision } & 20 \text { April } 2021 \\ & \text { Date of Acceptance } & 24 \text { April } 2021 & \text { Date of Publishing } & 28 \text { April } 2021\end{array}$

\footnotetext{
*Corresponding Author

Neurobiology, Research scholar, Department of Nutrition \& Dietetics, Faculty of Life Sciences, JSSAHER, Mysuru.
}

Funding This research did not receive any specific grant from any funding agencies in the public, commercial or not for profit sectors.

This article is under the CC BY- NC-ND Licence (https://creativecommons.org/licenses/by-nc-nd/4.0)

Copyright @ International Journal of Pharma and Bio Sciences, available at www.ijpbs.net

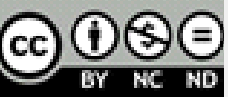

Int J Pharma Bio Sci., Volumel2., No 2 (April) 202I, pp I66-I72

Cltation Navya Raj MPI* Pooja G Singh I and Sushma BVI. , Act of phytochemical-based antioxidants in neurodegenerative disorders utilizing Indian medicinal plants.(202I).Int J Pharm Sci. I2(2), I66-I72

http://dx.doi.org/I0.22376/ijpbs.202I.12.2.b166-I72 


\section{INTRODUCTION}

Chiefly neurodegenerative diseases are a significant threat to human health. Such age-dependent conditions are becoming more common, resultantly due to the adverse effects of neurodegenerative processes that occur in elderly ${ }^{1,2}$. Etymologically, the term consists of prefix "Neuro", refers to nerve cells (i.e. neurons) and "degeneration", and refers to a phase of losing structure/function in the case of tissues or organs $^{3}$. Thus, neurodegeneration refers to any pathological condition that mainly affects neurons in the strict sense of the term. In fact, a wide group of neurological disorders with heterogeneous clinical and pathological expressions affecting specific subsets of neurons in specific functional anatomical structures constitute neurodegenerative diseases; they occur in a relentless way for unexplained reasons and development. Neurons, which include the brain and spinal cord, are the building blocks of the nervous system. Normally, neurons do not replicate or replace themselves, so they will not be replaced by the body when they become injured or die. ${ }^{4}$ Incurable and disabling disorders resulting in gradual degeneration / death of nerve cells or neurons in the human brain are neurodegenerative diseases. This causes movement disorders (called ataxias) or mental functioning issues (called dementias). ${ }^{4}$ Proposed investigation highlights the impact of neuro-protective effects of Indian medicinal plants promising to reverse the pathology of Alzheimer's and Parkinson's. finding explains the importance of herbal medicine plants in relation to neuro-protective activity and mechanisms of their action $^{4,5}$. Etiology with respect to the onset of disease inclination has its own molecules mechanism and clinical manifestations, in various pathogenic cascades, certain general pathways may be recognised. Disease progressions and vulnerability manifests with protein miss-folding and aggregation, oxidative stress and free radicals formation, metal dyshomeostasis, mitochondrial dysfunction, and impaired phosphorylation all occurring simultaneously, are included. ${ }^{6}$

\section{I.I AGING}

The complex physiological mechanism of morphological and biochemical modifications that gradually occur is recognised in aging ${ }^{7}$. The modifications include the CNS, shrinking of telomere, the hormonal and reproductive systems, the cardiovascular system. With the exception of family forms that can be determined to affect people younger than 60 , ageing remains the greatest risk issue for NDs. ${ }^{7,8,9}$. In recent decades' human life expectancy has increased particularly in developing countries, and age-related neurodegenerative, including Alzheimer disease and Parkinson disease, have become more prevalent as the population of the world grows older 8,10 . Although neuronal cell death is not always planned to occur at a selected age, ageing-related cell and molecular changes communicate with genes and environmental components to determine which cells are effectively ageing and on the road to neurodegeneration?. Mitochondrial dysfunction, multiple loose radical development and oxidative stress, microglia dysfunction, decreased chaperone output, decreased synaptic density, blood-brain barrier disturbance, and low range of neurogenesis are correlated with ageing, 90 . In addition to practical degradation of neuronal effects in age-related genetic disorders, the accumulation of mitochondrial DNA deletions in the ageing process ". The decline in antioxidant enzyme synthesis and function is also associated with oxidative neuronal damage within the ageing mind. Oxidative damage to mitochondrial DNA is thought to be due to free radicals of mitochondrial origin. Moreover, growing older comes with a transition in the composition of the fatty acids of the mobile membrane. Like arachidonic acids, PUFA is prevalent in the ageing of the brain and particularly susceptible to oxidative damage such as lipid peroxidation ${ }^{12}$. Histopathological transition also takes place in the neuroinflammatory brain with microglia morphology and pass time. Older microglia are also less mobile, less mobile and more somatic in younger organisms than microglia ${ }^{12}$. Microglial phagocytosis is also seen to shift within an elderly brain ${ }^{13}$, and the aged micro glyphs show enlarged phagosomal / lysosomal marker expression associated with this. Cognitive dysfunction, as well as some types of common neurodegenerative diseases such as $A D^{14}$, are also being shown to be an ordinary method for biologically active ageing since choline interest in key brain areas is being lost or declined.

\section{I.2 CLASSIFICATION OF NEURODEGENERATIVE DISEASES}

To date, the lion's share of focus has been paid towards understanding the onset of various neurodegenerative diseases, including $A D, P D, H D$ and amyotrophic lateral sclerosis $(A L S)^{3}$ as shown in Fig $I$. 


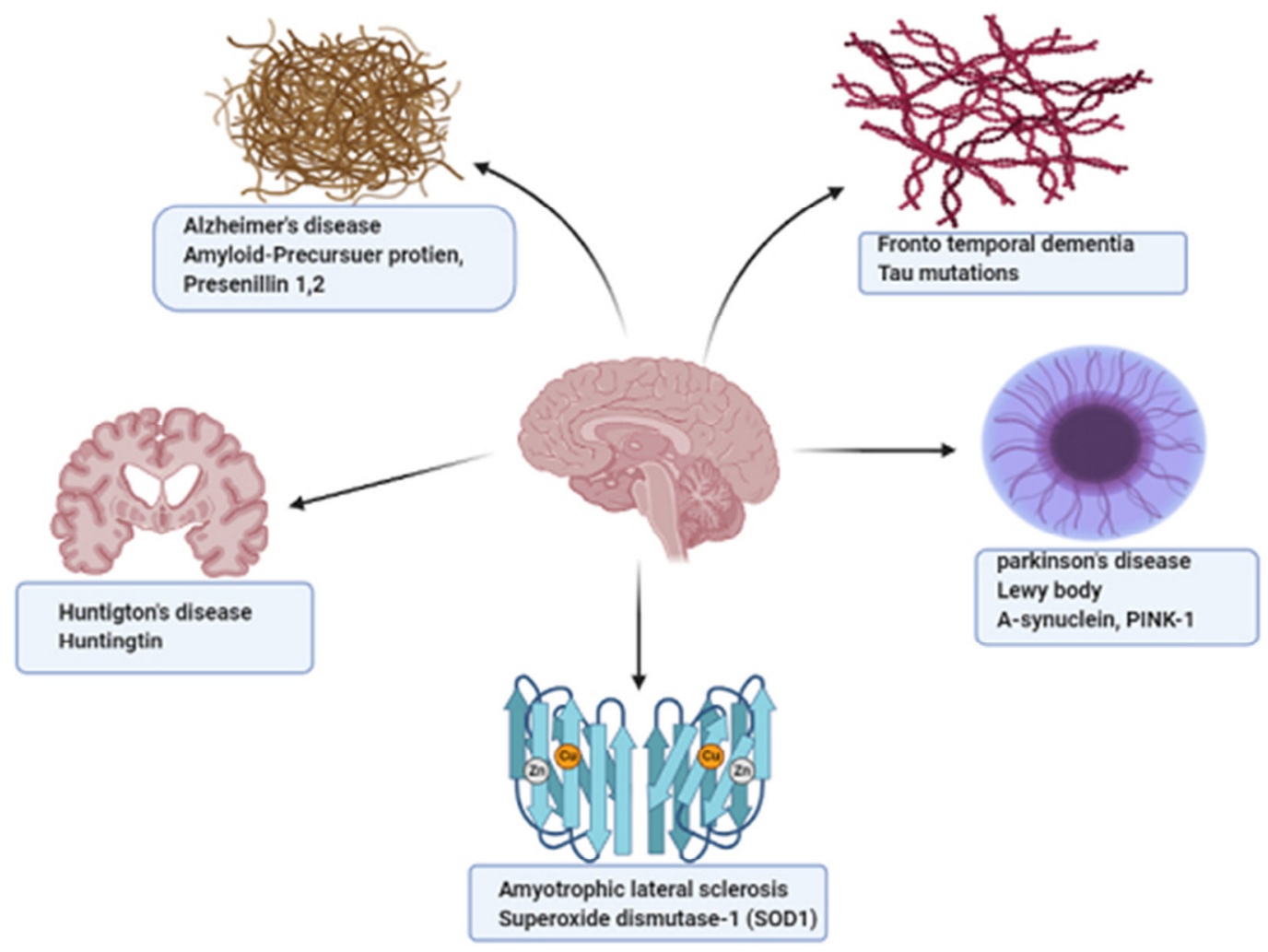

Fig I: Classification of neurodegenerative diseases ${ }^{39}$

\section{I.3 MULTIFACTORIAL FACTORS ASSOCIATED WITH NEURODEGENERATIVE DISEASE}

Neurodegenerative disorder comprises a series of pathological disorders occurring in the selected areas of the nervous system which are distinguished by sluggish progressives and permanent dysfunction and neuron depletion, defining clinical appearance and direction. multifactorial causes of hereditary, environmental and endogenous influences related to aging are known to be the main fundamental process contributing to neurodegenerative $e^{3,6}$.

\section{I.4 COMMON PATHOGENIC MECHANISMS UNDERLYING MANY NEURODEGENERATIVE DISEASES INCLUDE}

- Abnormal protein misfolding, proteasomal dysfunction and aggregation.

- Oxidative stress and formation of reactive oxygen species [ROS].

- Impaired bioenergetics, mitochondrial dysfunction and DNA damage.

- Fragmentation of neuronal Golgi apparatus.

- Dysfunction of neurotrophins. [NTFs]

- Neuro-inflammatory process.

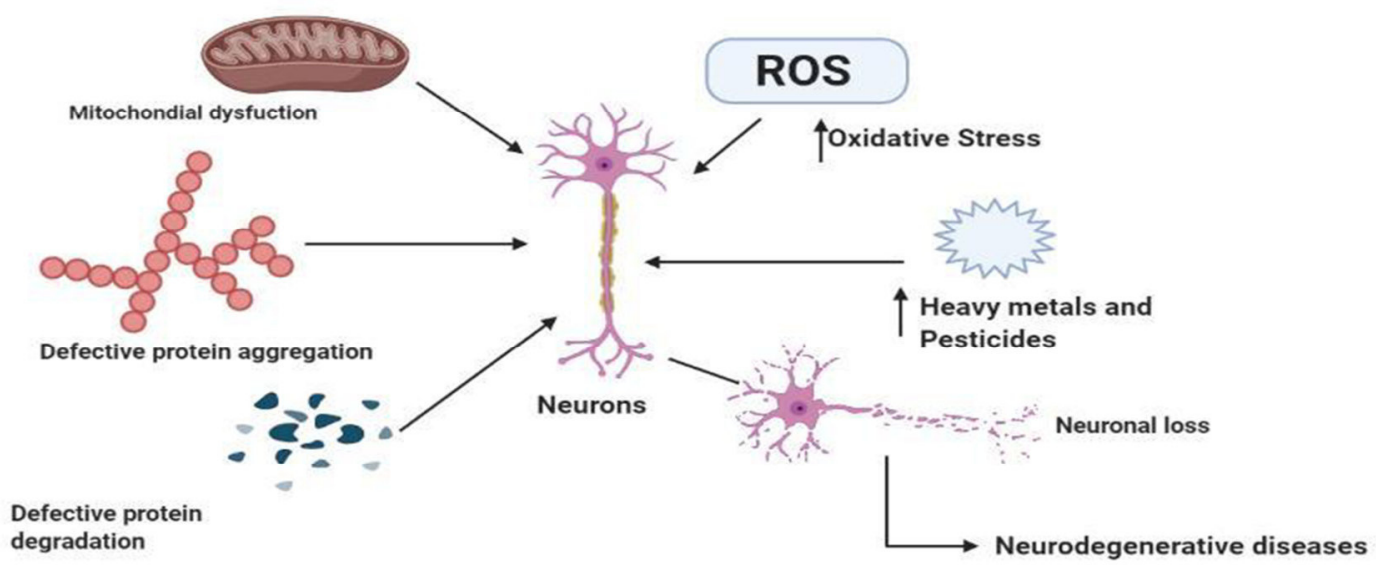

Fig 2: Genetic factors and environmental factors associated with neurodegenerative diseases ${ }^{6}$ 


\section{a) DYS-FUNCTIONING OF MITOCHONDRIA IN ND-}

Mitochondria are important cell survival regulators, death and mitochondrial power dysfunctions contributing to reduced ATP production, decreased calcium tamponing and increased reactive oxygen generation. Several research indicates that mitochondria plays a crucial function in ageing15,16. Energy metabolism and mitochondrial respiratory defects in $A D$ are features of neurodegeneration-impaired brain tissue but also in $A D$ patient peripheral cells. Biochemical research has been shown for/disrupting processes in the post-mortem $A D$ brains in three main enzymes: the dehydrogenase complex of pyruvate (PDHC), the mitochondrial cycle of a-ketoglutarate dehydrogenase complex (KGDHC) 17 .

\section{b) PROTEIN MISFOLDING AND AGGREGATION IN ND-}

Protein aggregates do not accumulate in stressed stable neurons owing, in part, to cell-like 'quality control machines;' molecular chaperones, for example, can have a toxicity defence mechanism because chaperones can inhibit and facilitate the refilling of proteins that have misfolded proteins in and between polypeptides. In addition to the regulation of the content of proteins produced by molecular chaperones, the defective or aberrant proteins are obvious from the framework of ubiquitin-proteasome system [UPS], and autophagy/lysosomal degradation. If the chaperones cannot fix misfolded proteins, they can be tagged for degradation by the proteasome with the addition of poly-ubiquitin chains. In ND conditions, the brain is expected to accumulate intra- or extracellular protein aggregates because of the reduction in molecular chaperone activity ${ }^{18}$

\section{c) OXIDATIVE STRESS IN ND-}

As a part of the cellular metabolism, the reactive oxygen species are usually generated in the cell of living organisms and are important to cellular homeostasis maintenance. Low to modest ROS concentrations function in mechanisms such as immune response, inflammation, synaptic plasticity, learning and memory in physiological settings ${ }^{19}$. The excess of the ROS production can be risky, creating adverse oxidative changes to the cell portion as the primary targets for ROS-induced disruption, including mitochondrial structures $^{20}$. The human body, however, has a number of antioxidants, such as [SOD] and glutathione systems, which counterbalance the effect of oxidants ${ }^{21}$. In the event of an imbalance between free radical development and detoxification, the production of ROS will overwhelm antioxidant resistance, leading to a noxious condition known as oxidant stress, and in general cellular degradation ${ }^{22,23}$ as shown in Fig 2.

\section{I.5 FUNCTIONAL ROLE OF MEDICINAL PLANTS AND ITS PHYTOCONSTITUENTS IN NEURODEGENERATION}

The use in dementia therapy of complementary drugs, such as plant extracts, differs according to various cultural practises. Neuro-endocrine-immune systems are modulated by Ayurvedic medicinal herbs and these are rich sources of compounds like antioxidants and anti-inflammatory ${ }^{14,24}$. It is assumed that they boost memory and rejuvenate cognitive functions ${ }^{25-27}$. Numerous Ayurveda medicinal herbs have been used in control and treatment of chronic and acute neurological disorders.

\begin{tabular}{|c|c|c|}
\hline \multicolumn{3}{|c|}{ Table I: Medicinal plants used in neurodegenerative diseases ${ }^{38}$} \\
\hline Medicinal Plants & Phytoconstituents & Mode of action \\
\hline Acorus calamus & Alpha \& beta asarone & Inhibits the acetylcholinesterase. \\
\hline Allium sativum & S-allylcysteine & $\begin{array}{l}\text { Improves locomotor function associated with increased } \\
\text { production of dopamine, decreased production of lipid } \\
\text { peroxidation \& superoxide and improves SOD operation }\end{array}$ \\
\hline Bacopa monnieri & $\begin{array}{l}\text { Bacoside, bacoside-A,mannitol, } \\
\text { sitosterol,betulinic acid }\end{array}$ & $\begin{array}{l}\text { Inhibits the degeneration of cholinergic and has cognitive } \\
\text { enhancement effects in rats. }\end{array}$ \\
\hline Centella asiatica & Asiatic acid and asiaticoside & Inhibits beta-amyloid cell death in vitro. \\
\hline $\begin{array}{l}\text { Convolvulus } \\
\text { pluricaulis }\end{array}$ & $\begin{array}{lr}\text { Convoline, } & \text { convolidine, } \\
\text { convolvine,confoline, } & \text { convozine, } \\
\text { kaempferol \& steroids phytosterol. }\end{array}$ & $\begin{array}{l}\text { In the hippocampal areas associated with memory/learning } \\
\text { functions, there has been a dose-related increase of AchE activity } \\
\text { in the CAI \& CA3 region. }\end{array}$ \\
\hline Curcuma longa & Essential oils, curcumin, polyphenol & \\
\hline Ginkgo biloba & $\begin{array}{l}\text { Ginkgolides } A, B, C, J \text { \& bilobalide, bi- } \\
\text { flavones, poly-prenols }\end{array}$ & $\begin{array}{l}\text { It functions to various degrees as free radical cells that are used to } \\
\text { minimise membrane fluidity and impaired cells observed with } A D \\
\text { in view of excessive fluid peroxidation mediators. }\end{array}$ \\
\hline Glycyrrhiza glabra & $\begin{array}{l}\text { Glycyrrhizin, glycyrrhizic \& } 2 \text { molecules } \\
\text { of glucuronic acid. }\end{array}$ & $\begin{array}{l}\text { Inhibition of viral fixation and replication of cell membranes and } \\
\text { intervention in cell signal transduction }\end{array}$ \\
\hline Withania somnifera & $\begin{array}{l}\text { Withanolide-A to } Y \text {, withasomniferols } A \\
\text { to } C \text {, withaferin A \& withanone. }\end{array}$ & $\begin{array}{l}\text { It has been shown to be free radicals formed by withaniamides } \\
\text { during initiation and progression of } A D \text {. Withaniamides avoided } \\
\text { the mortality of neuronal cells from amyloid plaques }\end{array}$ \\
\hline
\end{tabular}

Emerging evidence indicates that healthy lifestyles during life can reduce the likelihood of cognitive impairment in later life, or postpone the onset as shown in Table I. A small one-year delay in $A D$ onset by some form of lifestyle intervention is expected to result in 9.2 million fewer people with $A D$ globally by $2050^{28,29}$. Indeed, a third of $A D$ cases may be prevented through lifestyle changes, it has been suggested ${ }^{29,30}$. Food is not only the source of food \& energy, but there is a complementary treatment that can also offer health benefits. The use of functional foods and nutraceuticals as therapeutics allows diet therapy to be a safe method ${ }^{31}$. It has recently been suggested that a combination of nine risk factors is responsible for around 35 percent of dementia cases ${ }^{29,32}$. This includes early childhood education (up to 12 years), mid-life hypertension, mid-life obesity, hearing loss, late-life depression, diabetes, physical inactivity, smoking, and 
group isolation. Namely carotenoids and omega-3 FA, which are key nutritional components of $\mathrm{MeDi}$, this nutrition components role on cognition and AD is discussed below ${ }^{29}$.

\section{I.6 MEDITERRANEAN DIET- AS A THERAPEUTIC DIET REGIME}

Whole grains, fruits, vegetables, legumes, nuts, yoghurt, fish \& white meat as sources of protein are part of the Mediterranean conventional diet. The fruit \& vegetable-rich diet is associated with a low incidence of chronic degenerative disorder and decreases the risk of cancer, cardiovascular disease, relative to other countries in the Mediterranean population ${ }^{31,33}$. The neuro-protection fundamental mechanism provided by $\mathrm{MeDi}$ is yet to be understood. This diet provides you a rich source of antioxidants, unsaturated fatty acids and vitamins. Therefore, this $\mathrm{MeDi}$ has to be suggested as different nutritional components that operate synergistically and dose dependently to reduce or decrease the risk factors associated with $A D^{29,34}$.

\section{I.7 CAROTENOIDS AND ITS NEURO-PROTECTIVE PROPERTIES}

Carotenoids are plant pigments which are naturally ubiquitous and photosynthetic species that occur naturally (plants, algae, cyanobacteria) and certain non-photosynthetic organisms synthesise de novo. The lipid-soluble C40 compounds are carotenoids and are known as carotenes or xanthophyll. Importantly, they must derive from the diet mainly from the leaves of edible plants that are dark green, yellow, orange and red in colour, where humans cannot synthesise carotenoids de novo ${ }^{29,35}$. The basic mechanisms that underlie the relationship between carotenoids and cognitive health and function have not been thoroughly explained yet. Due to their chemical structure and localization within biological membranes, carotenoids are believed to be neuro-protective, thus providing antioxidant and anti-inflammatory properties at their storage locations. The processes involved in neurodegeneration can be mitigated by these properties, namely oxidative stress and inflammation ${ }^{29,36}$.

\section{I.8 NEURO-PROTECTIVE PROPERTIES OF OMEGA- 3-FA}

Fats and oils are an important part of the diet (and a significant component of $\mathrm{MeDi}$ ) in addition to carotenoids since they provide energy storage FAs and design the biological membranes of cells and their organelles. FAs are non-branched carbon, hydrogen, and acid molecules on one end. They may be completely saturated in their composition or have one or more saturations (double bonds). In its name and classification, the FA's number of carbons and unsaturations must be specified. It is not yet completely known the precise biochemical processes by which $x-3$ FAs transmit cognitive benefits. However, it has been suggested that their

\section{REFERENCES}

I. Gitler AD, Dhillon P, Shorter J. Neurodegenerative disease: models, mechanisms, and a new hope. Dis Model Mech. 2017;10(5):499-502. doi: $\underline{10.1242 / \mathrm{dmm} .030205}$, PMID 28468935. properties may lead to the reduction of $A D$ pathogenesis processes like inflammation. As described above, neuro inflammation is inflammation occurring within a CNS which can trigger neuronal death and synaptic dysfunction. Hence, it has been put forward that DHA played an important function in neuro-inflammation regulation and resolution. ${ }^{29,37}$. Herbal treatment, as a whole, offers potential solutions to current treatments for neurodegenerative diseases. Alternative medicine has been used since ancient times, and various extracts of medicinal plants and herbal formulas have shown promise for use in Neurodegenerative Diseases. Because of the presence of numerous chemical constituents and their ability to function on various biological targets, medicinal plants offer a fertile ground for new drug development 40 Medicinal plants and natural com- pounds, such as Withania somnifera (ashwagandha), Ginseng, curcumin, resveratrol, Baccopa monnieri, Ginkgo biloba, Tinospora cordifolia , Convolvulus pluricaulis and Wolfberry have been applied to prevent or alleviate neurological diseases and relief of neurological symptoms.

\section{CONCLUSION}

With recent accomplishments in $A D$ and $P D, H D$ and $A L S$ in view, neurodegenerative disorders tend to share many similar degenerative multifactorial mechanisms. Due to these multifactorial and clinical features, the platforms of gene expression analysis is commonly used to examine the altered pathways during degeneration and to classify possible biomarkers and drug goals. As a forum for the ancient Ayurvedic Medicine method, inclusive descriptions of plants used for neuroscience therapy have been offered in the latest study. The different phyto-constituents of various plants demonstrated the protective effect for Neurodegenerative diseases. Thus, the existences of bioactive chemicals are mostly responsible for the treatment, conducted over the last two decades that nutraceuticals are important to brains and can have a beneficial influence on cognition. It is proven that phytochemical constituents are important as a preventive measure for the optimization of cognition and neurologic disorders. Yet conformity with proper foods and access to good diets such as MeDi are one huge obstacle. With respect to MeDi, there is clear proof that it may play a beneficial effect on the cognitive health of healthy people and decrease the likelihood of contracting neurological disorders by following or adhering to this trend.

\section{AUTHORS CONTRIBUTION STATEMENT}

Navya Raj MP (NR) and Sushma BV(SBV) conceptualized the study. Navya Raj MP , Pooja G Singh (PS) and Sushma $\mathrm{BV}(\mathrm{SBV})$ drafted the manuscript and necessary inputs were given towards designing the Manuscript and helped with the discussion.

\section{CONFLICT OF INTEREST}

Conflict of interest declared none.
2. Heemels MT. Neurodegenerative diseases. Nature. 2016;539(7628):179. doi: 10.1038/539179a, PMID 27830810. 
3. Przedborski S, Vila $M$, Jackson-Lewis V. Neurodegeneration: what is it and where are we? J Clin Invest. 2003; III(I):3-10. doi: 10.1172/JCII7522, PMID 12511579.

4. Lalotra Sunali VJS. Scientific Reports of Medicinal Plants Used for the Prevention and Treatment of Neurodegenerative diseases. Pharm. Biosci J. 2019;7(I):I5-25. doi: 10.205 I0/ukjpb/7/il/I79297.

5. Mosconi L, Brys M, Switalski R, Mistur R, Glodzik L, Pirraglia E, Tsui W, De Santi S, De Leon MJ. Maternal family history of Alzheimer's disease predisposes to reduced brain glucose metabolism. Proc Natl Acad Sci U S A. 2007;104(48):19067-72. doi:

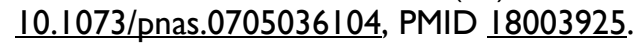

6. Sheikh S, Safia, Haque E, Mir SS. Neurodegenerative diseases: multifactorial conformational diseases and their therapeutic interventions. J Neurodegener Dis. 2013;2013:56348I. doi: 10.1155/2013/56348I, PMID 26316993.

7. Iriti M, Vitalini S, Fico G, Faoro F. Neuroprotective herbs and foods from different traditional medicines and diets. Molecules. 2010;15(5):3517-55. doi: 10.3390/molecules I50535I7, PMID 20657497.

8. Reeve A, Simcox E, Turnbull D. Ageing and Parkinson's disease: why is advancing age the biggest risk factor? Ageing Res Rev. 2014;14(I):19-30. doi: 10.1016/j.arr.2014.01.004, PMID 24503004.

9. Hindle JV. Ageing, neurodegeneration and Parkinson's dec- ease. Age Ageing. 2010;39(2):|56-6I. doi: 10.1093/ageing/afp223, PMID 20051606.

10. Migliore L, Coppedè F. Environmental-induced oxidative stress in neurodegenerative disorders and aging. Mutat Res. 2009;674(I-2):73-84. doi: $\underline{\text { 10.1016/j.mrgentox.2008.09.013, PMID } 18952194 .}$

II. Rubio-Perez JM, Morillas-Ruiz JM. A review: inflammatory process in Alzheimer's disease, role of cytokines. ScientificWorldjournal. 2012;2012, 15 pages:Article ID 756357. doi: 10.1100/2012/756357, PMID 22566778.

12. Hefendehl JK, Neher JJ, Sühs RBS, Kohsaka S, Skodras A, Jucker $M$. Homeostatic and injury-induced microglia behavior in the aging brain. Aging Cell. 2014;13(1):609. doi: 10.1 I | |/acel. I2 I49, PMID 23953759.

13. Mosher KI, Wyss-Coray T. Microglial dysfunction in brain aging and Alzheimer's disease. Biochem Pharmacol. 2014;88(4):594-604. doi: 10.1016/j.bcp.2014.01.008, PMID 24445162.

14. Perry EK, Kilford L, Lees AJ, Burn DJ, Perry RH. Increased Alzheimer pathology in Parkinson's disease related to antimuscarinic drugs. Ann Neurol. 2003;54(2):235-8. doi: 10.1002/ana.10639, PMID 12891676:

15. Beal MF, Shults CW. Effects of coenzyme QIO in Huntington's disease and early Parkinson's disease. BioFactors. 2003;|8(|-4):|53-6|. doi: 10.1002/biof.5520180218, PMID 14695931.

16. Beal MF. Mitochondria take center stage in aging and neurodegeneration. Ann Neurol. 2005;58(4):495-505. doi: 10.1002/ana.20624, PMID 16178023.

17. Small GW, Mazziotta JC, Collins MT, Baxter LR, Phelps ME, Mandelkern MA, Kaplan A, La Rue A, Adamson CF, Chang L. Apolipoprotein E type 4 allele and cerebral glucose metabolism in relatives at risk for familial Alzheimer disease. JAMA. 1995;273(12):942-7, PMID 7884953.
18. Muchowski PJ, Wacker JL. Modulation of neurodegeneration by molecular chaperones. Nat Rev Neurosci. 2005;6(1):II-22. doi: 10.1038/nrn I587, PMID I56II723.

19. Kishida KT, Klann E. Sources and targets of reactive oxygen species in synaptic plasticity and memory. Antioxid Redox Signal. 2007;9(2):233-44. doi: 10.1089/ars.2007.9.ft-8, PMID 17II5936.

20. Rego AC, Oliveira CR. Mitochondrial dysfunction and reactive oxygen species in excitotoxicity and apoptosis: implications for the pathogenesis of neurodegenerative diseases. Neurochem Res. 2003;28(I0):1563-74. doi: 10.1023/a:10256826||389, PMID $\underline{14570402 .}$.

21. Indo HP, Yen HC, Nakanishi I, Matsumoto K, Tamura M, Nagano Y, Matsui H, Gusev O, Cornette R, Okuda $T$, Minamiyama $Y$, Ichikawa $H$, Suenaga $S$, Oki $M$, Sato T, Ozawa T, Clair DK, Majima HJ. A mitochondrial superoxide theory for oxidative stress diseases and aging. J Clin Biochem Nutr. 2015;56(I):1-7. doi: 10.3164/jcbn. 14-42, PMID 2583430I.

22. Grimm A, Friedland K, Eckert A. Mitochondrial dysfunction: the missing link between aging and sporadic Alzheimer's disease. Biogerontology. 20I6;I7(2):28I-96. doi: 10.1007/s 10522-015-96I8-4, PMID 26468143.

23. Cobley JN, Fiorello ML, Bailey DM. 13 Reasons why the brain is susceptible to oxidative stress. Redox Biol. 2018;15:490-503. doi: 10.1016/j.redox.2018.01.008, PMID 2941396I.

24. Aruoma OI, Bahorun T, Jen LS. Neuroprotection by bioactive components in medicinal and food plant extracts. Mutat Res. 2003;544(2-3):203-15. doi: 10.1016/j.mrrev.2003.06.017, PMID $\underline{\text { |4644322. }}$.

25. Ferrari CKB. Functional foods, herbs and nutraceuticals: towards biochemical mechanisms of healthy aging. Biogerontology. 2004;5(5):275-89. doi: 10.1007/s 10522-004-2566-z, PMID I5547316.

26. Zhao J. Nutraceuticals, nutritional therapy, phytonutrients and phytotherapy for improvement of human health: a perspective on plant biotechnology application. Rec Pat Biotechnol. 2007; I(I):75-97. doi: 10.2174/187220807779813893, PMID 19075834.

27. Vecchia C, Bosetti C. Diet and cancer risk in Mediterranean countries. Hung Med J. 2007 Jan I;I (I):I3-23. doi: I0.I556/HM].I.2007.I.3.

28. Brookmeyer R, Johnson E, Ziegler-Graham K, Arrighi $H M$. Forecasting the global burden of Alzheimer's disease. Alzheimers Dement. 2007;3(3):186-9|. doi: 10.1016/j.jalz.2007.04.381, PMID 19595937.

29. Power R, Prado-Cabrero A, Mulcahy R, Howard A, Nolan JM. The role of nutrition for the aging population: implications for cognition and Alzheimer's disease. Annu Rev Food Sci Technol 10:61939.https://doi. 2019;10:619-39. doi: 10.1146/annurev-food-030216, PMID 30908950.

30. Barnes DE, Yaffe K. The projected effect of risk factor reduction on Alzheimer's disease prevalence. Lancet Neurol. 201 I;10(9):819-28. doi: 10.1016/S14744422(I I)70072-2, PMID 217752I3.

31. McClatchey WC, Mahady GB, Bennett BC, Shiels L, Savo V. Ethnobotany as a pharmacological research tool and recent developments in CNS-active natural products from ethnobotanical sources. Pharmacol 
Ther. 2009;123(2):239-54. doi: 10.1016/j.pharmthera.2009.04.002, PMID 1942285I.

32. Livingston G, Sommerlad A, Orgeta V, Costafreda SG, Huntley J, Ames D, Ballard C, Banerjee S, Burns A, Cohen-Mansfield J, Cooper C, Fox N, Gitlin LN, Howard R, Kales HC, Larson EB, Ritchie K, Rockwood K, Sampson EL, Samus Q, Schneider LS, Selbæk G, Teri L, Mukadam N. Dementia prevention, intervention, and care. Lancet. 2017;390(I0II3):2673734. doi: $10.1016 / 50140-6736(17) 31363-6$, PMID 28735855.

33. Solanki I, Parihar P, Parihar MS. Neurodegenerative diseases: from available treatments to prospective herbal therapy. Neurochem Int. 2016;95:100-8. doi: 10.1016/j.neuint.2015.11.001, PMID 26550708.

34. Aridi YS, Walker JL, Wright ORL. The association between the Mediterranean dietary pattern and cognitive health: a systematic review. Nutrients.

38. sunali lalotra*, J S Vaghela. Scientific reports of medicinal plants used for the prevention and treatment of Neurodegenrative diseases. ISSN: 25820540. Pharmaceutical and Biosciences journal. Nov 2018.

39. Ramavati pal*, Jan Larsen, Simon Geir Moller.chapter 2-The potential of proteomics in understanding
2017;9(7):E674. doi: 10.3390/nu9070674, PMID 28657600.

35. Alcaíno J, Baeza M, Cifuentes V. Carotenoid distribution in nature. Subcell Biochem. 2016;79:3-33. doi: 10.1007/978-3-319-39126-7_ I, PMID 27485217.

36. Mohammadzadeh Honarvar $\mathrm{N}$, Saedisomeolia A, Abdolahi M, Shayeganrad A, Taheri Sangsari G, Hassanzadeh Rad B, Muench G. Molecular antiinflammatory mechanisms of retinoids and carotenoids in Alzheimer's disease: a review of current evidence. J Mol Neurosci. 2017;6I(3):289-304. doi: 10.1007/s |2031-016-0857-x, PMID 2786466I.

37. McDougle DR, Watson JE, Abdeen AA, Adili R, Caputo MP, Krapf JE, Johnson RW, Kilian KA, Holinstat M, Das A. Anti-inflammatory $\omega-3$ endocannabinoid epoxides. Proc Natl Acad Sci U S A. 2017; I I4(30):E6034-43. doi: 10.1073/pnas. 1610325II4, PMID 28687674.

Neurodegeneration. International journal of Neurobiology, voll21, 2015, pages25-28.

40. Jogender Mehla ',*, Pooja Gupta ${ }^{2, *}$, Monika Pahuja ${ }^{3}$, Deepti Diwan ' and Diksha Diksha . Indian Medicinal Herbs and Formulations for Alzheimer's Disease, from Traditional Knowledge to Scientific Assessment. MDPI, I0 December 2020. 